\title{
Combining shared control with variability over surface features: Effects on transfer test performance and task involvement
}

Citation for published version (APA):

Corbalan, G., Kester, L., \& Van Merriënboer, J. (2009). Combining shared control with variability over surface features: Effects on transfer test performance and task involvement. Computers in Human Behavior, 25(2), 290298. https://doi.org/10.1016/j.chb.2008.12.009

DOI:

10.1016/j.chb.2008.12.009

Document status and date:

Published: 01/03/2009

Document Version:

Peer reviewed version

Please check the document version of this publication:

- A submitted manuscript is the version of the article upon submission and before peer-review. There can be important differences between the submitted version and the official published version of record. People interested in the research are advised to contact the author for the final version of the publication, or visit the DOI to the publisher's website.

- The final author version and the galley proof are versions of the publication after peer review.

- The final published version features the final layout of the paper including the volume, issue and page numbers.

Link to publication

\section{General rights}

Copyright and moral rights for the publications made accessible in the public portal are retained by the authors and/or other copyright owners and it is a condition of accessing publications that users recognise and abide by the legal requirements associated with these rights.

- Users may download and print one copy of any publication from the public portal for the purpose of private study or research.

- You may not further distribute the material or use it for any profit-making activity or commercial gain

- You may freely distribute the URL identifying the publication in the public portal.

If the publication is distributed under the terms of Article 25fa of the Dutch Copyright Act, indicated by the "Taverne" license above, please follow below link for the End User Agreement:

https://www.ou.nl/taverne-agreement

Take down policy

If you believe that this document breaches copyright please contact us at:

pure-support@ou.nl

providing details and we will investigate your claim.

Downloaded from https://research.ou.nl/ on date: 26 Apr. 2023 
1Running head: SHARED CONTROL AND TASK VARIABILITY

This is a pre-print of:

Corbalan, G., Kester, L., \& Van Merriënboer, J. J. G. (2009). Combining shared control with variability over surface features: Effects on transfer test performance and task involvement. Computers in Human Behavior, 25, 290-298.

Copyright Elsevier, available online at: http://www.elsevier.com/wps/find/journaldescription.cws_home/759/description\#description

Combining Shared Control with Variability over Surface Features: Effects on Transfer Test Performance and Task Involvement

Gemma Corbalan $^{\mathrm{a}}$, Liesbeth Kester ${ }^{\mathrm{a}}$, and Jeroen J. G. van Merriënboer ${ }^{\mathrm{b}}$

${ }^{a}$ Educational Technology Expertise Center, Open University of the Netherlands, Heerlen, The Netherlands

${ }^{\mathrm{b}}$ Netherlands Laboratory for Lifelong Learning, Open University of the Netherlands, Heerlen, The Netherlands

Author Note

Correspondence concerning this article should be addressed to Gemma Corbalan, Open University of the Netherlands, Educational Technology Expertise Center, P.O. Box 2960, 6401 DL, Heerlen, the Netherlands. T: +31 45 5762909; F: +31 45 5762907;

E: gemma.corbalan@ou.nl

Acknowledgement. This research was funded by the Netherlands Organization for Scientific Research (NWO, The Hague, project no. 411-02-107-V). 


\begin{abstract}
Positive effects of learner control decrease when learners do not perceive the control given to them, make suboptimal choices, or are cognitively overloaded by the amount of choice. This study proposes shared control (i.e., learners choose from a pre-selection of suitable tasks) over highly variable tasks to tackle these problems. Ninety-four students participated in a $2 \times 2$ factorial experiment with the factors control (system, shared) and variability of surface features (low, high). Results show superior effects on training performance, transfer test performance, and task involvement of shared control when learners can choose from pre-selected tasks with surface features that are different from the surface features of previous tasks.
\end{abstract}

Key words: Cognitive load, learner control, surface features, system control, variability. 
Combining Shared Control with Variability over Surface Features: Effects on Transfer Test Performance and Task Involvement

Recent instructional theories advocate on-demand methods of instruction in which learners are given freedom to choose their own learning path (Bell \& Kozlowski, 2002; Schnackenberg \& Sullivan, 2000; Williams, 1996). In contrast to system-controlled instruction, learner-controlled instruction allows learners to make their own decisions on specific elements of instruction. These include, for example, the instructional components (e.g., learning tasks, information elements), the component characteristics (e.g., task contexts, modality of presented information), as well as task sequence and instructional pace. Instructional locus of control can be thought of as a continuum ranging from full system control to full learner control, involving several forms of shared control (Hannafin, 1984). Learner control is believed to positively influence learning and motivation (Kinzie \& Sullivan, 1989; Ross, Morrison, \& O’Dell, 1989; Schnackenberg \& Sullivan, 2000; Williams, 1996). It permits learners to adapt particular characteristics of the learning material to their individual preferences and needs (Kinzie, 1990; Merrill, 1994), and has been theorized to be a useful alternative to the classical aptitude-treatment interaction approach in that learners can become system independent (Federico, 1980).

Although the beneficial effects of learner control are supported from a theoretical perspective, empirical research shows both beneficial and detrimental effects on learning. These inconsistent results suggest that learner control can be either motivating or de-motivating (Katz \& Assor, 2007). According to Skinner (1996), there is little consensus on the kinds of control that are beneficial or harmful for learning and on how these may interact with certain learner and situational characteristics. In any case, the unconditional use of learner control is not supported (Freitag \& Sullivan, 1995; Lin \& Hsieh, 2001; Skinner, 1996; Williams, 1996). Potential threats of learner control include, amongst others: (1) a lack of perception of control 
when learners do not see the choices provided as sufficiently different from each other; (2) making suboptimal choices because learners are not aware what is best for their learning, and (3) a high cognitive load on learners' processing resources influenced by the amount of choice available. Well-designed instruction should prevent these potential pitfalls and ensure the necessary conditions to optimize learner control.

First, with regard to perception of control, some authors (Cordova \& Lepper, 1996; Katz \& Assor, 2007; Kinzie, 1990; Langer, 1975; Lepper, 1985; Taylor \& Brown, 1988) argue that the positive effects of learner control remain apparent even when the choices provided are irrelevant for learning and the control is merely an illusion. In a study carried out by Cordova and Lepper (1996), participants who were given control over aspects of the task that were not relevant for learning (e.g., the names of the characters of a computer game designed to teach arithmetical and problem-solving skills) scored significantly higher on a posttest than participants who did not have control at all. In a recent study, Hasler, Kersten, and Sweller (2007) found that participants in learner-paced conditions achieved higher learning efficiency despite the fact that the control options were rarely used. The mere availability of control had an added value on learning, since the instructional content was identical in both system paced and learner paced conditions. In addition, when learners do not perceive that they are in control of something this decreases performance and increases frustration, especially when they are still forced to make a selection (Burger \& Cooper, 1979). Accordingly, perception of control refers to the individual belief of how much control is available (Skinner, 1996). In line with this idea, many theorists (Averill, 1973; Burger, 1989; Skinner, 1996) argue that learner control is only a powerful predictor of functioning and positively related to performance if it is actually perceived as control by the learners (Savage, Perlmuter, \& Monty, 1979). 
Furthermore, when learners perceive they are in control of something, they will most likely be engaged in learning activities, and will actually allocate their cognitive resources to learning because of the satisfaction derived from just performing the task (Deci, Vallerand, Pelletier, \& Ryan, 1991; Fisher \& Ford, 1998; Keller, 1983; Salomon, 1983, 1985). When learners are willing to invest mental effort in learning, this may in turn positively influence performance (Paas \& van Gog, 2006; Volet, 1997). In this respect, perceived learner control is believed to increase learners' involvement. An involved learner will most likely invest more mental effort in performing the learning tasks, which might result in higher learning outcomes (Kinzie, 1990; Paas,Tuovinen, van Merriënboer, \& Darabi, 2005). Accordingly, lack of perceived control decreases learners' involvement in learning, threatening learning outcomes.

Second, novice learners commonly make suboptimal choices due to a lack of sufficient or adequate domain knowledge. If learners select what they like rather than what they need, learner control may even have negative effects on learning. For instance, learners may reduce instructional time by skipping or omitting considerable amounts of instructional materials essential for good performance (Merrill, 2002; Ross \& Morrison, 1989; Snow, 1980; for a review, see Williams, 1996). Hence, learners with insufficient or inadequate knowledge should not be allowed to make instructional choices unless they are taught or supported to make the right selections first. With shared control, for example, the learner may make the final selection of one learning task from a subset of suitable tasks, which are pre-selected from all available tasks by an instructional agent (e.g., a teacher or computer system).

In addition, learners may opt to select learning tasks with highly similar surface features (i.e., irrelevant aspects of the task that are not directly related to goal attainment) because those tasks are more familiar to them. In a study by Ross, McCormick, and Krisak (1986), college students majoring in nursing or education were allowed to select from several alternative themes (e.g., sports, medical, educational, abstract) to learn statistics. They found that nursing 
students tended to select the medical theme while education students tended to select the educational theme. Hence, when learners exercise contextual control, such as over surface features, this may make instruction more personally relevant to them without affecting the basic lesson content (Hannafin, 1984; Kinzie, 1990). However, learner control over context may ultimately be detrimental for learning since learners may tend to continuously select similar contexts. Increased exposure to a variety of contexts is believed to promote transfer (Ross \& Morrison, 1989). Variability over surface features, which enables learners to distinguish taskrelevant from task-irrelevant information, encourages the adaptation to new tasks. Providing learners with learning tasks representing a high variability of surface features has been shown to facilitate the construction of more general problem-solving rules. Thus, it helps learners to abstract away from the contexts and to focus on those components that are shared by the learning tasks, enhancing transfer of learning to new, unfamiliar situations (Chen \& Mo, 2004; Holyoak \& Koh, 1987; Quilici \& Mayer, 1996). This abstraction process requires the mindful engagement of the learners, increasing their "germane" cognitive load (i.e., load caused by cognitive processes that directly contribute to learning; Clark, Nguyen, \& Sweller, 2005; Paas \& van Merriënboer, 1994; Sweller, van Merriënboer, \& Paas, 1998; van Merriënboer, Kester, \& Paas, 2006; van Merriënboer, Schuurman, de Croock, \& Paas, 2002).

Surface features, such as species in inheritance tasks because the rules for the transmission of hereditary characteristics from parent organisms to their offspring are the same for animals, plants, and humans, are often more perceptible for learners than structural features, such as the parents' genes composition in inheritance tasks (Cummins, 1992; Gick \& Holyoak, 1987; Quilici \& Mayer, 1996, 2002). Learners who are presented a subset of learning tasks that differ in surface features from prior tasks will most likely recognize those differences, perceive the choices as being valuable and use this information to make tasks more relevant for them when provided with control (Katz \& Assor, 2007; Kinzie, 1990). Hence, learner control over 
task selection may positively influence their perception of control - as compared to learners who are presented with one 'system selected' task - and thus their involvement and transfer performance. Learners who are presented with a subset of tasks with surface features similar to that of prior tasks, in contrast, will recognize the lack of differences. This may even lead to frustration, especially when they are still forced to make a selection (Burger \& Cooper, 1979) which may negatively influence their perception of control and thus their involvement in learning and performance on transfer tasks. Hence, to enhance the perception of control the choices provided to learners should be attractive ones (Kinzie, 1990). In this study, the provision of a subset of variable tasks is presented to make choices more attractive (Keller, 1983). In addition and at least equally important, learners who are given a subset of learning tasks differing in surface features from prior tasks are prevented from making suboptimal choices because all the tasks they can choose from differ from the prior one with regard to their surface features. As argued above, this ensures a certain amount of variability which is expected to facilitate transfer of learning.

Third, learner control may introduce potential problems with excessive cognitive load (Scheiter \& Gerjets, 2007; Schwartz, 2004). Even experienced learners may become overwhelmed and demotivated by an excessive amount of choice, for instance, when they are provided with hundreds of tasks to choose from (Iyengar \& Lepper, 2000; Schwartz, 2004). In this respect, learners may experience difficulties in selecting, sequencing, and pacing huge amounts of information because of cognitive overload (Scheiter \& Gerjets, 2007). However, several studies (Fry, 1972; Kinzie \& Sullivan, 1989; Lahey, Hurlock, \& McCann, 1973) show that the majority of learners actually prefer some control. Hence, providing learners with a limited amount of choice may avoid the potential pitfalls of a too high amount of choice and yet grant a desired amount of learner control. This is realized when an instructional agent (e.g., a teacher or a computer program) and the learner share control over the process of task selection 
(Corbalan, Kester, van Merriënboer, 2006; Tennyson \& Buttery, 1980). In this two-step process, a computer program first selects a subset of learning tasks with desirable task features (e.g., surface features) based on task features of previously selected tasks (system control). Second, the learner selects from this subset one task to work on (learner control). This prevents overloading the learners' cognitive resources, while still giving them a sense of control and preventing them from making wrong instructional decisions (Kinzie \& Sullivan, 1989). Hence, this study implements shared control to prevent cognitive overload by reducing the amount of choice given to learners.

To sum up, for learner control to be effective, learners must both perceive they are in control of something and be supported to make optimal choices - otherwise learner control may even hamper learning. Variability in the surface features of learning tasks helps to meet these requirements since (a) it enhances the perception of control and, in combination with shared control, (b) it prevents learners of making suboptimal choices because the subset of tasks they may choose from ensures a high variability, which is a prerequisite to abstraction and transfer. Furthermore, shared control prevents cognitive overload by reducing the amount of possible choices given to the learners. The purpose of this study is to investigate under which conditions shared control is optimized. Shared control is hypothesized to increase learners' involvement in learning and yield higher performance on transfer tasks provided that high variability over surface features of tasks is ensured; shared control in combination with low variability may even decrease learners' involvement and yield lower performance on transfer tasks.

\section{Method}

\section{Participants}

Ninety-four first year students (90 females and 6 males) in the Health Sciences domain of a Dutch school for secondary Vocational Education and Training (VET) participated in this study. Their mean age was 17.48 years $(S D=2.04)$. A 2 × 2 factorial design was used to study 
the effects of control (system control vs. shared control) and variability of surface features in the learning tasks (low variability vs. high variability). All participants received a movie DVD for their participation. They were randomly assigned to one of the four experimental groups: system control with low variability $(n=22)$; system control with high variability $(n=25)$; shared control with low variability $(n=23)$; and shared control with high variability $(n=24)$.

\section{Materials}

Electronic learning and testing environment. The electronic learning environment was a web application containing an introduction to the domain of genetics, a factual knowledge test, the learning tasks, the transfer test, and mental effort questions to estimate cognitive load.

Introduction. The introduction included the main concepts of the domain of genetics necessary to begin the training (i.e., dominant and recessive genes, homozygous or heterozygous gene pairs, genotype and phenotype) and a worked-out example containing all the problem-solving steps of a representative inheritance task.

Factual knowledge test. The factual knowledge test contained 16 multiple choice questions. Five items were not included in the analysis because those items had a negative itemtest correlation. The maximum test score was 11 points. The reliability of the test was .62 (Cronbach's alpha).

Learning tasks. The electronic learning environment was connected to a database which contained 162 completion tasks about inheritance mechanisms of acquired traits that apply to different species and traits (e.g., hair, fur or leaf color). Completion tasks present a given state, a goal state, and a partial solution that learners have to complete. Table 1 shows the features of the learning tasks in the database: the first column contains species and species type (within brackets), and the second column contains traits per species type and trait parts (within brackets). These are the surface features of the tasks. In addition, depending on the parents' gene forms for a certain trait, three crossing types can be distinguished for each trait in each 
species, which leads to three different types of solutions. Crossing types depend on whether the parents are homozygous (i.e., the two gene forms - dominant or recessive - for one trait are identical) or heterozygous (i.e., the two gene forms for one gene are different) for a trait. These are the structural features of the tasks.

\section{[Insert Table 1 about here]}

Each participant completed twelve learning tasks. After each learning task, two multiple choice questions with four answer options were presented to the learners. Each correct question scored one point and each wrong question scored zero points, leading to a maximum score of twenty-four points. The reliability of the learning-tasks questions was .95 (Cronbach's alpha). An example question is: "what are the expected genotypes for coat length of the puppies?"

Transfer test. The transfer test consisted of 12 transfer tasks, divided in 6 near transfer tasks and 6 far transfer tasks. The near transfer tasks were analogous to the learning tasks but contained different surface features (i.e., other subjects within the species, e.g., a fish, and other traits, e.g., the swimming pattern of a fish) and determined whether participants were able to apply the learned procedures. The far transfer tasks differed in structural features and were meant to determine whether participants were able to apply the learned procedures to new situations. The following tasks were used for far transfer: (a) a dihybrid crossing task which required two different traits to be treated separately; (b) a family tree task in which participants had to infer the genotype of one of the parents based on the information of one of the grandparents; (c) a task in which participants had to infer the genotype of an individual from information from the relatives given; (d) a second generation task that required learners to determine the offspring of the offspring, (e) a co-dominant genes task, that is, genes that are equally strong and both expressed, and (f) a task in which participants must apply the acquired knowledge in a bottom-up way, that is, using the information of the offspring to find out 
information of the parents. The maximum test score was 12 points. The reliability of the test was .83 (Cronbach's alpha).

Mental effort. After each learning task and transfer test task, participants' perceived mental effort was measured as the 'effort required to complete the task' with a one-item 7-point rating scale (Paas, 1992; Paas, Tuovinen, Tabbers, \& van Gerven, 2003). Mental effort scores during training and transfer are an average of the scores of the twelve learning tasks and the twelve transfer tasks, respectively. Reliability of the mental effort measures reported during the training was .97 and during the transfer test .95 (Cronbach's alpha).

Motivation questionnaires. After the 12 learning tasks, participants completed five 7point rating scales (i.e., perceived ability, effort, interest, usefulness, and intrinsic motivation) of the Intrinsic Motivation Inventory (IMI; Deci, Eghrari, Patrick, \& Leone, 1994). The scales contained, in order, five, five, seven, four, and nine items. Reliability analysis (Cronbach's alpha) of the IMI scales yielded internal consistencies of $.76, .70, .90, .83$, and .67 , respectively. In addition, participants completed two 7-point rating scales (i.e., control beliefs - 4 items - and self-efficacy - 8 items -) of the Motivated Strategies for Learning Questionnaire (MSLQ; Garcia \& Pintrich, 1994). Reliability analysis of the MSLQ scales yielded, in order, Cronbach's alphas of .76 and .91.

Time logging. The electronic learning environment kept track of the time (in minutes) participants needed to complete each learning task and transfer test task.

Learners' involvement. In this study, task involvement (Paas et al., 2005) was used as an indicator of learners' involvement. Based on the assumption that motivation, mental effort and performance are positively related, task involvement is computed by combining transfer test performance and mental effort invested during training. According to Paas et al. (2005), low mental effort combined with low test performance can be considered indicative of low task involvement, whereas high mental effort combined with a high test performance is indicative of 
a high task involvement. To calculate task involvement, transfer test scores and mental effort scores are first standardized and the $z$-scores are entered into the formula (Paas et al., 2005):

$$
\text { Task Involvement }=\frac{z_{\text {Transfer Score }}+z_{\text {Mental Effort }}}{\sqrt{2}}
$$

\section{Procedure}

Training phase. Prior to the training phase, participants received the basic introduction and the factual knowledge test. After that, participants received the 12 learning tasks (i.e., completion tasks) and the associated mental effort measures. During the training phase, the 12 tasks were dynamically selected as follows: in the system control conditions, the system selected and presented each time only one task to the participant. In the shared control conditions, the system randomly pre-selected three tasks from six possible tasks resulting from the combination of species types (x3) and part traits (x2) and presented these three tasks to the participant, from which the participant selected one task to perform. In the low variability conditions, the species (i.e., human, animal or plant) and trait (i.e., colour, shape or length) of the first (range of) learning task(s) was randomly selected and counterbalanced over participants. Each next (range of) task(s) was selected from all available tasks featuring the same species and trait as the prior task, thus species and trait remained invariable throughout the training. In the high variability conditions, the species and trait of the first (range of) learning task(s) were randomly selected. Each next (range of) task(s) was selected from tasks featuring a different species and a different trait than the previously performed task. Figure 1 shows an example of a possible sequence of three learning tasks performed in both the low and high variability conditions. 
Moreover, each of the three crossing types (i.e., homozygous x homozygous, heterozygous $\mathrm{x}$ heterozygous, and homozygous $\mathrm{x}$ heterozygous) was randomly selected to avoid a practice bias. Once the learner performed a learning task with a certain crossing type four times, remaining tasks with this crossing type were deleted from the database, leading to a total of twelve learning tasks (four learning tasks for each of the three crossing types). This assured that every learner practiced all the solution-relevant aspects.

Test phase. Directly after the training, participants filled out the scales corresponding to the IMI and the MSLQ. One week after the first session, the participants performed the transfer test. After each test item, mental effort measures were taken.

\section{Results}

An ANOVA on the factual knowledge test filled out by the participants prior to the training revealed no difference between conditions $(F(1,90)<1)$. Therefore, all subsequent analyses are performed using ANOVAs with between-subjects factors variability and control. For all statistical tests a significance level of .05 was maintained. Table 2 provides an overview of the mean scores and standard deviations for the dependent variables during training and transfer.

[Insert Table 2 about here]

\section{Training Results}

Due to technical difficulties, there were seven system-missing values corresponding to seven participants on one of the mental effort values measured across the 12 learning tasks. Each missing value was replaced by the mean mental effort on the remaining 11 tasks of that particular participant during the training phase.

An ANOVA revealed no main effects for control $(F(1,90)=.25, n s)$ and variability $(F$ $(1,90)=.091, n s)$ on training performance, but there was a significant interaction effect $(F(1$, $\left.90)=4.51, M S E=173.85, p<.05, \eta_{p}^{2}=.05\right)$. As Figure 2 shows, with high variability shared 
control yields better training performance than system control, but with low variability system control yields better performance than shared control. Post-hoc multiple comparisons using Bonferroni's adjustment shows no significant differences between the different conditions.

[Insert Figure 2 about here]

No effects on training time were found for control $(F(1,90)=2.24, n s)$, variability $(F$ $(1,90)=.012, n s)$, and their interaction $(F(1,90)=.14, n s)$. Also no effects on mean mental effort invested during training were found for control $(F(1,90)=.009, n s)$, variability $(F(1$, $90)=.16, n s)$, and their interaction $(F(1,90)=.155, n s)$.

\section{Test Results}

Only the data of participants who attended the second session of the experiment $(N=$ 86) could be included in the analysis of test results. The number of participants that dropped out $(n=8)$ was evenly distributed over the conditions $\left(X^{2}=.29, p=.96\right)$. This resulted in the following group composition: system control with low variability $(n=22)$; system control with high variability $(n=21)$; shared control with low variability $(n=22)$; and shared control with high variability $(n=21)$.

No main effects were found for control $(F(1,82)=.018, n s)$ and variability $(F(1,82)=$ $.751, n s)$ on transfer test performance, but there was a significant interaction effect $(F(1,82)=$ 4.310, $\left.M S E=33.68, p<.05, \eta_{p}^{2}=.05\right)$. As Figure 3a shows, with high variability shared control yields better transfer test performance than system control, but with low variability this pattern is reversed. Post-hoc multiple comparisons were conducted using Bonferroni's adjustment. These comparisons revealed that participants in the shared control with high variability condition $(M=7.04, S D=2.80)$ outperformed participants in the shared control with low variability condition $(M=5.26, S D=2.46)$. Thus, as hypothesized, shared control yields highest transfer test results provided that high variability over surface features is ensured. The other comparisons revealed no differences. 
[Insert Figure 3 about here]

No main effects were found for control $(F(1,82)=.829, n s)$ and variability $(F(1,82)=$ $.690, n s)$ on task involvement, but again an interaction effect occurred $(F(1,82)=5.043, M S E$ $\left.=2.992, p<.05, \eta_{p}^{2}=.06\right)$. As Figure $3 \mathrm{~b}$ shows, with high variability shared control yields higher task involvement than system control, whereas with low variability this pattern is reversed. Post-hoc multiple comparisons were conducted using Bonferroni's adjustment. These comparisons revealed that participants in the shared control with high variability condition $(M$ $=.24, S D=.68)$ were more involved in the tasks than participants in the shared control with low variability condition $(M=-.27, S D=.79)$. The other comparisons revealed no differences.

Analyses revealed no significant main effects for control $(F(1,82)=.538, n s)$, variability $(F(1,82)=.418, n s)$, and their interaction $(F(1,82)=.02, n s)$ on the time spent on the transfer test. Also no effects on mean mental effort invested during the transfer tests were found for control $(F(1,82)=.003, n s)$, variability $(F(1,82)=.056, n s)$, and their interaction $(F(1,82)=.717, n s)$.

\section{Motivation questionnaire}

Table 3 provides an overview of the mean scores and standard deviations for the scales of the motivation questionnaire.

[Insert Table 3 about here]

A main effect of variability on participants' reported self-efficacy was found, $F(1,90)=$ 4.294, MSE $\left.=5.675, p<.05, \eta_{p}^{2}=.05\right)$. Participants in the system control conditions reported higher self-efficacy $(M=4.98, S D=1.11)$ than participants in the shared control conditions $(M$ $=4.49, S D=1.17)$. No effects were found on any of the other scales.

\section{Discussion}

This study investigated whether shared control over the selection of learning tasks, in which a computer system first makes a pre-selection of tasks and the learner makes the final 
selection, might be optimized by ensuring variability of the surface features of the learning tasks (i.e., species and traits in inheritance tasks). Learners who made a selection from learning tasks with surface features different from the previous task were expected to reach a higher transfer test performance, and be more involved in learning than learners who made a selection from learning tasks with surface features very similar to the previous task. We found support for this hypothesis. The observed interactions show that the shared control groups were influenced by the low/high variability provided whereas the system control groups did not. In addition, participants in the group with shared control and high variability of surface features achieved higher transfer test performance, and were more involved in learning than participants in the group with shared control and low variability of surface features.

These findings are in line with the explanation for the effect of control and variability on transfer suggested by Gay (1986). According to this author, learner control is more efficient under conditions in which learners have a well established conceptual understanding of the content domain. In our study, participants in the shared control with high variability condition in which schema construction is believed to be promoted by the successive presentation of varied instances - may have quickly achieved superior understanding of the genetic content. Therefore, they might have profited more from shared control than participants in the shared control with low variability condition, in which schema construction was not facilitated because the tasks to choose from were very similar to the previous tasks.

Moreover, despite the fact that in the shared control conditions the available choice concerned task aspects irrelevant for goal attainment (i.e., surface features which were more perceptible or more salient for the learners than the structural features), participants profited more from the given control when the surface features of the tasks to choose from were different from the surface features of the previous task. If participants have control but can only choose from tasks similar to the previous task, they may not see the meaning of making a 
selection, possibly leading to frustration (Burger \& Cooper, 1979), less involvement in learning, and lower performance. Accordingly, when choices are provided, the degree to which individuals perceive they are in control seems to be related to the level of attractiveness of the choices available (Kehoe, 1979). Choosing from tasks that are different from the previous one appears to be more attractive than choosing from tasks that are very similar to the previous one. This may have made participants in the shared control with high variability condition be more receptive to the instructional material than participants in the shared control with low variability condition, who probably perceived less control. This supports the idea that perception of control is a condition sine qua non. Without the perception of control, which may be optimized by task variability, learners' involvement in learning is low and shared control does not work.

Nevertheless, participants in the shared control with high variability condition performed no higher than participants in the two system-controlled conditions on any of the variables. A plausible reason could be that the choices provided to the learners, including learners in the high variability conditions, were rather restricted (i.e., including a different species and trait than the prior task, but still limited to one species and trait) and learners may have seen the provided choices as not sufficiently different from each other. Consequently, although our results on the transfer test and on involvement supported our hypothesis, conclusions based on these interaction effects should be drawn with caution. Future studies should include direct measures of perceived control to uncover whether learners' perception of control in a shared control with high variability condition is indeed higher than in other conditions.

With regard to the learners' performance during training, the found interaction of control and variability is not surprising and further supports the added value of shared control, provided that the perception of control is enhanced by high variability of the surface features of the learning tasks. Whereas the value of shared control was enhanced when the tasks to choose 
from were different from the previous task (high variability), system control could have been influenced by such a higher variability. For the system control groups, repeatedly presenting a task with similar surface features might have made the sequence of learning tasks easier to perform during training than repeatedly presenting a task with new surface features.

Participants in the system control conditions reported higher self-efficacy than participants in the shared control conditions. In the MLSQ, the definition of self-efficacy involves the expectancy for success and judgments of one's ability to accomplish a task and confidence to perform a task (Garcia \& Pintrich, 1994). The results of this study seem to indicate that when the sequence of tasks is system-controlled, learners have more confidence that they will be able to perform the task. Selecting own tasks may thus cause learners to become more insecure. As in other studies on learner control (e.g., Williams, 1996), no differences on the other scales of the motivation questionnaire were found. This could be a typical disadvantage of short laboratory experiments. Future studies may investigate the effects of shared control in more authentic learning environments and may also study the effects of giving learners a higher amount of control than in the current study, where it was limited to choosing between three tasks. A higher level of control could be achieved, for instance, by allowing learners to choose between more learning tasks that differ in their - similar and dissimilar - surface features and possibly also their structural features.

Another possible explanation for the lack of effects on measures of motivation is that after twelve learning tasks participants were used to the mode of task selection, which might have reduced possible differences at the end of the training. For instance, measuring motivation after three or four tasks, instead of after the whole training, could have been a more sensitive measure of the effects of variability of surface features of tasks on motivation. Future studies may also investigate learners' perception of control over task selection. The 'perceived autonomy' scale included in the IMI, which was included in this study, turned out to be not 
very valuable because it was highly unreliable $(\alpha=.28)$ and only partially measured the perception of control as applied in this study.

Regarding the results on the mean mental effort, no significant effects were found but the observed pattern is in accordance with cognitive load theory (CLT; Sweller, 1988; Sweller et al., 1998; van Merriënboer \& Sweller, 2005). According to CLT, mental effort during training would be higher when variability is high, as a result of the germane load associated with the construction of more general rules, which in turn leads to lower mental effort during transfer test performance. In this study, overall cognitive load was reduced by using completion tasks, by limiting the choice available, and by randomizing variability on structural features (the mean mental effort invested during training lies below the neutral score of 4 in all conditions). Nevertheless, in the low variability conditions the mean mental effort during training was slightly lower than in the high variability conditions, and the mean mental effort invested on transfer test performance showed the reverse pattern. Moreover, shared control with low and high variability led, in order, to the lowest and the highest mean mental effort during training, and, again in order, to the highest and the lowest mean mental effort during transfer test performance. Future studies should further investigate the relationship between variability over surface features and mean mental effort. Furthermore, more sensitive cognitive load measures that make a distinction between germane and overall load may reveal more powerful results, especially when the amount of learning tasks to choose from is increased.

In this study it has been assumed that learners in the shared control with high variability condition would recognize the differences between learning tasks and that this would increase their perceived control. However, none of these two variables was directly measured. In general, future studies may also investigate the effects of providing learners with shared control over the selection of more complex tasks or the selection of tasks in other learning domains. Another route for future research pertains to the effects of further increasing the variability of 
surface features of learning tasks. Increasing variability, for instance, by including other groups of humans, animals, and plants, and by broadening the number of inherited traits, such as diseases or physical variations (e.g., being right or left handed in humans, ears that stand up or hang down in animals, or position of the flower in some plants), may have revealed more powerful effects of variability as a result of stronger schema formation. In addition, in our study variability on the structural features was randomized across all conditions. Whereas in the low variability conditions the variability was limited to one species and one trait, in the high variability conditions the surface features varied from each precedent task. Varying both structural and surface features could have masked any positive effect of the variability in surface features. Future studies should study the effects of providing learners with variability over the surface features when variability on structural features is predetermined.

Besides, the maximum amount of learner control that may be provided, especially when both surface and structural features vary highly, requires further investigation since they may easily overwhelm learners when provided together. Besides, completion tasks integrate the presentation of new information (in the given part of the solution) and the practice of problemsolving steps that have already been introduced (in the to-be-completed part of the solution). In our study, variability only referred to the presentation of surface features in the given part of the solution. Futures studies may investigate next to the effects of presentation variability, the effects of "practice variability" (i.e., practicing problem-solving steps that have not been practiced in the previous task) on transfer test performance and cognitive load. A final observation concerns the fact that $93,75 \%$ of the participants in our study was female. Future research is needed to determine whether the results can also be found in other domains and with another population of learners (e.g., with mostly males or with a similar proportion of males and females). 
To conclude, this study shows that when learners are provided with shared control, transfer test performance and involvement in learning are enhanced if learners can choose from learning tasks with surface features that are distinctly different from surface features of previously performed tasks. In this respect, this study complements the attempts of other authors to determine guidelines for implementing learner control (Hannafin, 1984; Scheiter \& Gerjets, 2007). Our findings are particularly important for instructional designers because more and more educational curricula use forms of on-demand education, in which learners can plan their own learning trajectory by choosing from authentic, real-life tasks. Our study shows that those curricula should ensure that available learning tasks are sufficiently different from each other and, most importantly, teachers should provide learners with selection options that ensure an optimal selection. 


\section{Acknowledgements}

The authors thank Monito for programming the electronic learning environment, and the students and coordinators of the Arcus College, Joep Gulikers and Hans Collijn, for their participation and collaboration. 


\section{References}

Averill, J. R. (1973). Personal control over aversive stimuli and its relationship to stress. Psychological Bulletin, 80, 286-303.

Bell, B. S., \& Kozlowski, A. W. J. (2002). Adaptive guidance: Enhancing self-regulation, knowledge, and performance in technology-based training. Personnel Psychology, 55, 267-304.

Burger, J. M. (1989). Negative reactions to increases in perceived personal control. Journal of Personality and Social Psychology, 56, 246-256.

Burger, J. M., \& Cooper, H. M. (1979). The desirability of control. Motivation and Emotion, 3, 381-393.

Chen, Z., \& Mo, L. (2004). Schema induction in problem solving: A multidimensional analysis. Journal of Experimental Psychology: Learning, Memory, and Cognition, 30, 583-600.

Clark, R. C., Nguyen, F., \& Sweller, J. (2005). Efficiency in learning. San Francisco, CA: Pfeiffer.

Corbalan, G., Kester, L., \& van Merriënboer, J. J. G. (2006). Towards a personalized task selection model with shared instructional control. Instructional Science, 34, 399-422.

Cordova, D. I., \& Lepper, M. R. (1996). Intrinsic motivation and the process of learning: Beneficial effects of contextualization, personalization, and choice. Journal of Educational Psychology, 88, 715-730.

Cummins, D. D. (1992) The role of analogical reasoning in the induction of problem categories. Journal of Experimental Psychology: Learning, Memory, and Cognition, 18, 1103-1124.

Deci, E. L., Eghrari, H., Patrick, B. C., \& Leone, D. (1994). Facilitating internalization: The self-determination theory perspective. Journal of Personality, 62, 119-142.

Deci, E. L., Vallerand, R. J., Pelletier, L. G., \& Ryan, R. M. (1991). Motivation and education: The self-determination perspective. Educational Psychologist, 26, 325-346. 
Federico, P. A. (1980). Adaptive instruction: Trends and issues. In R. E. Snow, P. A. Federico, \& W. E. Montage (Eds.), Aptitude, learning, and instruction: Vol. 1. Cognitive process analyses of aptitude (pp. 1-26). Hillsdale, NJ: Erlbaum.

Fisher, S. L., \& Ford, J. K. (1998). Differential effects of learner effort and goal orientation on two learning outcomes. Personnel Psychology, 51, 397-420.

Freitag, E. T., \& Sullivan, H. J. (1995). Matching learner preference to amount of instruction: An alternative form of learner control. Educational Technology, Research, and Development, 43, 1042-1629.

Fry, J. P. (1972). Interactive relationship between inquisitiveness and learner control of instruction. Journal of Educational Psychology, 63, 459-465.

Garcia, T., \& Pintrich, P. R. (1994). Regulating motivation and cognition in the classroom: The role of self-schemas and self-regulatory strategies. In D. H. Schunk \& B. J. Zimmerman (Eds.), Self-regulation of learning and performance: Issues and educational applications (pp. 127-153). Hillsdale, NJ: Erlbaum.

Gay, G. (1986). Interaction of learner control and prior understanding in computer-assisted video instruction. Journal of Educational Psychology, 78, 225-227.

Gick, M., \& Holyoak, J. (1987). The cognitive basis for knowledge transfer. In S. Cormier \& J. Hagman (Eds.), Transfer of learning: Contemporary research and applications (pp. 946). San Diego, CA: Academic Press.

Hannafin, M. J. (1984). Guidelines for using locus of instructional control in the design of computer-assisted instruction. Journal of Instructional Development, 7(3), 6-10.

Hasler, B. S., Kersten, B., \& Sweller, J. (2007). Learner control, cognitive load and instructional animation. Applied Cognitive Psychology, 21, 713-729.

Holyoak, K. J., \& Koh, K. (1987). Surface and structural similarity in analogical transfer. Memory and Cognition, 15, 332-340. 
Iyengar, S. S., \& Lepper, M. (2000). When choice is demotivating: Can one desire too much of a good thing?. Journal of Personality and Social Psychology, 79, 995-1006.

Katz, I., \& Assor, A. (2007). When choice motivates and when it does not. Educational Research Review, 19, 429-442.

Kehoe, J. F. (1979). Choice time and aspects of choice alternatives. In L. C. Perlmuter \& R. A. Monty (Eds.), Choice and perceived control (pp. 67-82). Hillsdale, NJ: Erlbaum.

Keller, J. M. (1983). Motivational design of instruction. In C. M. Reigeluth (Ed.), Instructional-design theories and models: An overview of their current status (pp. 383434). Hillsdale, NJ: Erlbaum.

Kinzie, M. B. (1990). Requirements and benefits of effective interactive instruction: Learner control, self-regulation, and continuing motivation. Educational Technology, Research and Development, 38(1), 1-21.

Kinzie, M. B., \& Sullivan, H. J. (1989). Continuing motivation, learner control, and CAI. Educational Technology, Research and Development, 37(2), 5-14.

Lahey, G. F., Hurlock, R. E., \& McCann, P. H. (1973). Post-lesson remediation and learner control of branching in computer-based learning. ERIC \#ED 083-797.

Langer, E. J. (1975). The illusion of control. Journal of Personality and Social Psychology, 32, 311-328.

Lepper, M. R. (1985). Microcomputers in education. American Psychologist, 40(1), 1-18.

Lin, B., \& Hsieh, C. (2001). Web-based teaching and learner control: A research review. Computers and Education, 37, 377-386.

Merrill, M. D. (1994) Instructional design theory. Englewood Cliffs, NJ: Educational Technology Publications. 
Merrill, M. D. (2002). Instructional strategies and learning styles: Which takes precedence?. In R. A. Reiser \& J. V. Dempsey (Eds.), Trends and issues in instructional technology (pp. 99-106). Columbus, OH: Prentice Hall.

Paas, F. (1992). Training strategies for attaining transfer of problem-solving skills in statistics: A cognitive-load approach. Journal of Educational Psychology, 84, 429-434.

Paas, F., Tuovinen, J., Tabbers, H., \& Van Gerven, P. W. M. (2003). Cognitive load measurement as a means to advance cognitive load theory. Educational Psychologist, $38,63-71$.

Paas, F., Tuovinen, J., van Merriënboer, J. J. G., \& Darabi, A. (2005). A motivational perspective on the relation between mental effort and performance: Optimizing learner involvement in instruction. Educational Technology, Research and Development, 53(3), 25-34.

Paas, F., \& van Gog, T. (2006). Optimising worked example instruction: Different ways to increase germane cognitive load. Learning and Instruction, 16, 87-91.

Paas, F., \& van Merriënboer, J. J. G. (1994). Instructional control of cognitive load in the training of complex cognitive tasks. Educational Psychology Review, 6, 51-71.

Quilici, J. L., \& Mayer, R. E. (1996). Role of examples in how students learn to categorize statistics word problems. Journal of Educational Psychology, 88, 144-161.

Quilici, J. L., \& Mayer, R. E. (2002). Teaching students to recognize structural similarities between statistics word problems. Applied Cognitive Psychology, 16, 325-342.

Ross, S. M., McCormick, D., \& Krisak, N. (1986). Adapting the thematic context of mathematical problems to students interests: Individual versus group-based strategies. Journal of Educational Research, 79, 245-252. 
Ross, S. M., \& Morrison, G. R. (1989). In search of a happy medium in instructional technology research: Issues concerning external validity, media replication, and learner control. Educational Technology, Research and Development, 37(1), 19-33.

Ross, S. M., Morrison, G. R., \& O’Dell, J. K. (1989). Uses and effects of learner control of context and instructional support in computer-based instruction. Educational Technology, Research and Development, 37(4), 29-39.

Salomon, G. (1983). The differential investment of mental effort in learning from different sources, Educational Psychologist, 18, 42-50.

Salomon, G. (1985). Information technologies: What you see is not (always) what you get. Educational Psychologist, 20, 207-216.

Savage, R. E., Perlmuter, L. C., \& Monty, R. A. (1979). Effect of reduction in the amount of choice and the perception of control on learning. In L. C. Perlmuter \& R. A. Monty (Eds.), Choice and perceived control (pp. 91-102). Hillsdale, NJ: Erlbaum.

Scheiter, K., \& Gerjets, P. (2007). Learner control in hypermedia environments. Educational Psychology Review, 19, 285-307

Schnackenberg, H. L., \& Sullivan, H. J. (2000). Learner control over full and lean computerbased instruction under differing ability levels. Educational Technology, Research and Development, 48(2), 19-35.

Schwartz, B. (2004). The paradox of choice: Why more is less. New York: Ecco.

Skinner, E. A. (1996). A guide to constructs of control. Journal of Personality and Social Psychology, 71, 549-570.

Snow, R. E. (1980). Aptitude, learner control, and adaptive instruction. Educational Psychologist, 15, 151-158.

Sweller, J. (1988). Cognitive load during problem solving: Effects on learning. Cognitive Science, 12, 257-285. 
Sweller, J., van Merriënboer, J. J. G., \& Paas, F. (1998). Cognitive architecture and instructional design. Educational Psychology Review, 10, 251-296.

Taylor, S. E., \& Brown, J. D. (1988). Illusion and well-being: A social psychological perspective on mental health. Psychological Bulletin, 103, 193-210.

Tennyson, R. D. \& Buttery, T. (1980). Advisement and management strategies as design variables in computer-assisted instruction. Educational Communication and Technology Journal, 28(3), 169-176.

Van Merriënboer, J. J. G., Kester, L., \& Paas, F. (2006). Teaching complex rather than simple tasks: Balancing intrinsic and germane load to enhance transfer of learning. Applied Cognitive Psychology, 20, 1-10.

Van Merriënboer, J. J., G., Schuurman, J. G., de Croock, M. B. M., \& Paas, F. (2002). Redirecting learners' attention during training: Effects on cognitive load, transfer test performance and training efficiency. Learning and Instruction, 12, 11-37.

Van Merriënboer, J. J. G., \& Sweller, J. (2005). Cognitive load theory and complex learning: Recent developments and future directions. Educational Psychology Review, 17, 147-177. Volet, A. (1997). Cognitive and affective variables in academic learning: The significance of direction and effort in students' goals. Learning and Instruction, 7, 235-254.

Williams, M. D. (1996). Learner-control and instructional technologies. In D. H. Jonassen (Ed.), Handbook of research for educational communications and technology (pp. 957982). New York: Simon \& Schuster Macmillan. 
Table 1

Composition of the Database with Learning Tasks

\begin{tabular}{|c|c|c|c|c|}
\hline Species & Traits (part traits) & Crossing type I & Crossing type II & Crossing type III \\
\hline & & $\begin{array}{c}\text { Homozygous } \\
\text { parent } \\
\text { x } \\
\text { Homozygous } \\
\text { parent }\end{array}$ & $\begin{array}{c}\text { Homozygous } \\
\text { parent } \\
x \\
\text { Heterozygous } \\
\text { parent }\end{array}$ & $\begin{array}{l}\text { Heterozygous } \\
\text { parent } \\
\text { x } \\
\text { Heterozygous } \\
\text { parent }\end{array}$ \\
\hline $\begin{array}{c}\text { Humans } \\
\text { (European, African, } \\
\text { Asian) }\end{array}$ & $\begin{array}{c}\text { Colour (hair/eyes) } \\
\text { Shape (eyelashes/nose) } \\
\text { Length (hair/thumb finger) }\end{array}$ & 18 Tasks & 18 Tasks & 18 Tasks \\
\hline $\begin{array}{c}\text { Animals } \\
\text { (dog, cat, guinea pig) }\end{array}$ & $\begin{array}{l}\text { Colour (hair/eyes) } \\
\text { Shape (ear/hair) } \\
\text { Length (tail/fur) }\end{array}$ & 18 Tasks & 18 Tasks & 18 Tasks \\
\hline $\begin{array}{c}\text { Plants } \\
\text { (pea, corn, bean) }\end{array}$ & $\begin{array}{l}\text { Colour (flower/leaf) } \\
\text { Shape (axis/fruit) } \\
\text { Length (fruit/pod) }\end{array}$ & 18 Tasks & 18 Tasks & 18 Tasks \\
\hline
\end{tabular}


Table 2

Results of the Training Phase and the Test Phase

\begin{tabular}{|c|c|c|c|c|c|c|c|c|}
\hline & \multicolumn{4}{|c|}{ Low Variability } & \multicolumn{4}{|c|}{ High Variability } \\
\hline & \multicolumn{2}{|c|}{ System control } & \multicolumn{2}{|c|}{ Shared control } & \multicolumn{2}{|c|}{ System control } & \multicolumn{2}{|c|}{ Shared control } \\
\hline & $M$ & $S D$ & $M$ & $S D$ & $M$ & $S D$ & $M$ & $S D$ \\
\hline Factual knowledge test & 6.05 & 2.50 & 5.60 & 2.57 & 5.65 & 2.29 & 5.79 & 2.05 \\
\hline \multicolumn{9}{|l|}{ Training } \\
\hline Time (min.) & 17.92 & 3.48 & 16.92 & 4.17 & 18.15 & 5.45 & 16.51 & 2.82 \\
\hline Performance $(\max .=24)$ & 17.73 & 5.87 & 15.64 & 6.73 & 15.39 & 6.75 & 18.75 & 5.34 \\
\hline Mental Effort $(\max .=7)$ & 3.35 & 1.41 & 3.22 & 1.41 & 3.36 & 1.36 & 3.44 & 1.05 \\
\hline \multicolumn{9}{|l|}{ Test } \\
\hline Time (min.) & 36.24 & 9.42 & 38.15 & 13.35 & 37.93 & 11.55 & 39.62 & 10.74 \\
\hline Performance $(\max .=12)$ & 6.43 & 2.86 & 5.26 & 2.46 & 5.70 & 3.04 & 7.04 & 2.80 \\
\hline Mental Effort (max. = 7) & 4.35 & 1.14 & 4.60 & 1.23 & 4.30 & 1.40 & 4.24 & 1.07 \\
\hline Task Involvement & 0.14 & 0.79 & -0.27 & 0.79 & -0.10 & 0.81 & 0.24 & 0.68 \\
\hline
\end{tabular}


Table 3

Results of the Motivation Questionnaire

Low Variability

High Variability

\begin{tabular}{lcccccccc} 
& \multicolumn{3}{c}{ System control } & \multicolumn{2}{c}{ Shared control } & \multicolumn{2}{c}{ System control } & \multicolumn{2}{c}{ Shared control } \\
\cline { 2 - 9 } & $M$ & $S D$ & $M$ & $S D$ & $M$ & $S D$ & $M$ & $S D$ \\
\hline Perceived ability & 4.03 & 1.03 & 4.27 & 1.18 & 4.32 & 1.25 & 4.12 & 1.10 \\
Effort & 4.58 & 1.04 & 4.85 & 1.26 & 4.48 & 1.19 & 4.46 & 1.01 \\
Interest & 3.85 & 1.24 & 3.71 & 1.49 & 4.01 & 1.56 & 1.48 & 1.31 \\
Use & 4.25 & 1.26 & 3.80 & 1.27 & 4.07 & 1.57 & 3.58 & 1.32 \\
Intrinsic Motivation & 4.43 & .73 & 4.59 & 1.02 & 4.56 & .96 & 4.37 & .86 \\
Control Beliefs & 5.60 & 1.10 & 4.85 & 1.47 & 5.38 & 1.18 & 5.15 & 1.04 \\
Self-Efficacy & 5.12 & 1.07 & 4.5 & 1.34 & 4.84 & 1.15 & 4.48 & 1.08 \\
\hline
\end{tabular}




\section{Figure Captions}

Figure 1. Example of a sequence of three learning tasks in the low variability condition (upper row) and the high variability condition (lower row).

Figure 2. Interaction of variability and control on training performance.

Figure 3. Interaction of variability and control on transfer test performance (A) and task involvement (B). 
Figure 1

Task 1

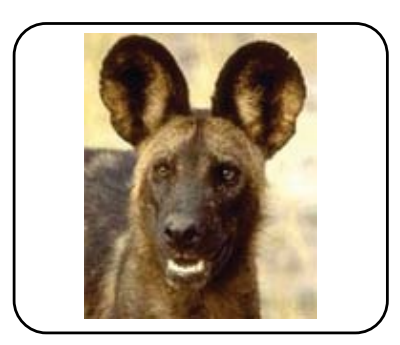

Species: Animal (dog)

Trait: Shape (round ears)

Task 1

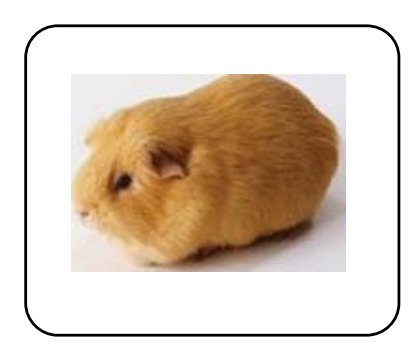

Species: Animal (guinea-pig)

Trait:
Task 2

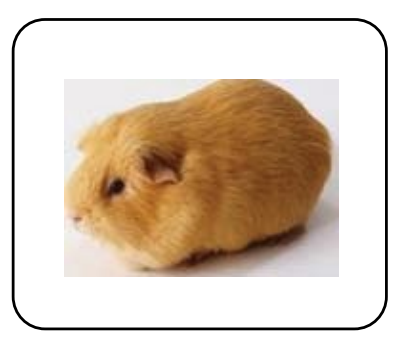

Species: Animal (guinea-pig)
Trait: $\quad$ Shape (straight fur)

Task 2

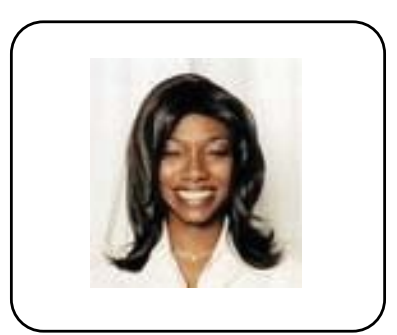

Species: Human (African) Trait: Colour (black hair)
Task 3

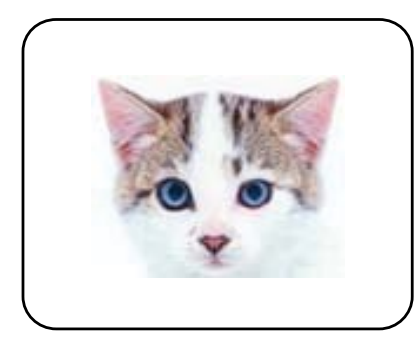

Species: Animal (cat)

Trait: $\quad$ Shape (pointed ears)

Task 3

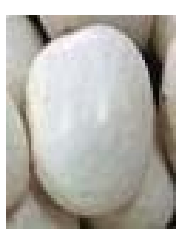

Species: Plant (bean plant)

Trait: $\quad$ Shape (round bean seed) 
Figure 2

Interaction Effect on Training Performanc

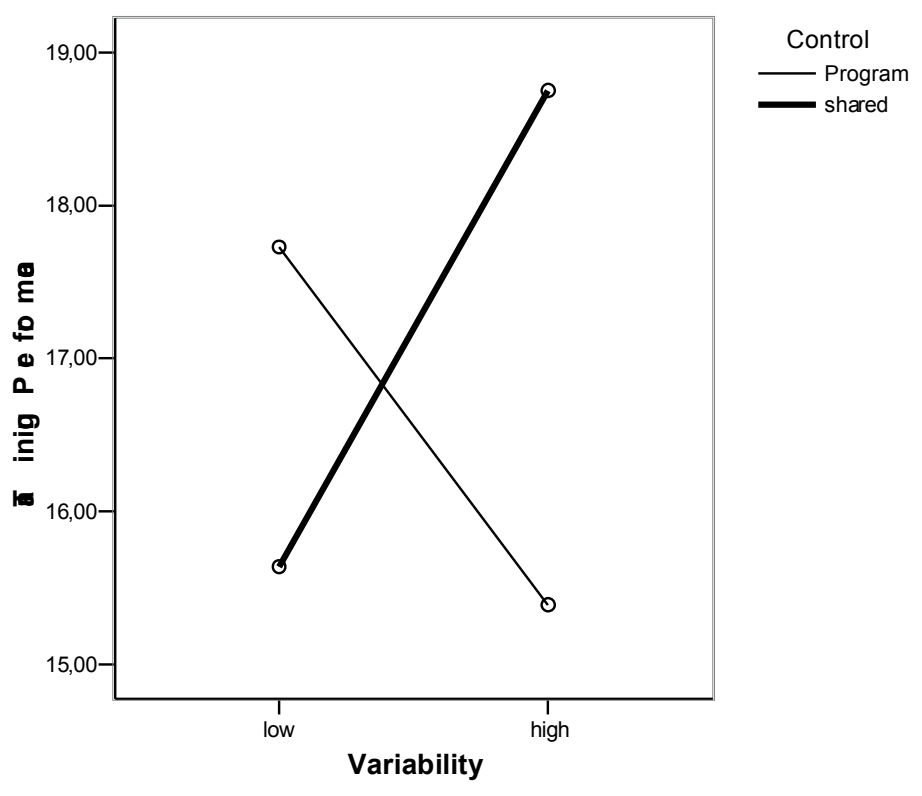


Figure 3

Interaction Effect on Transfer Performance

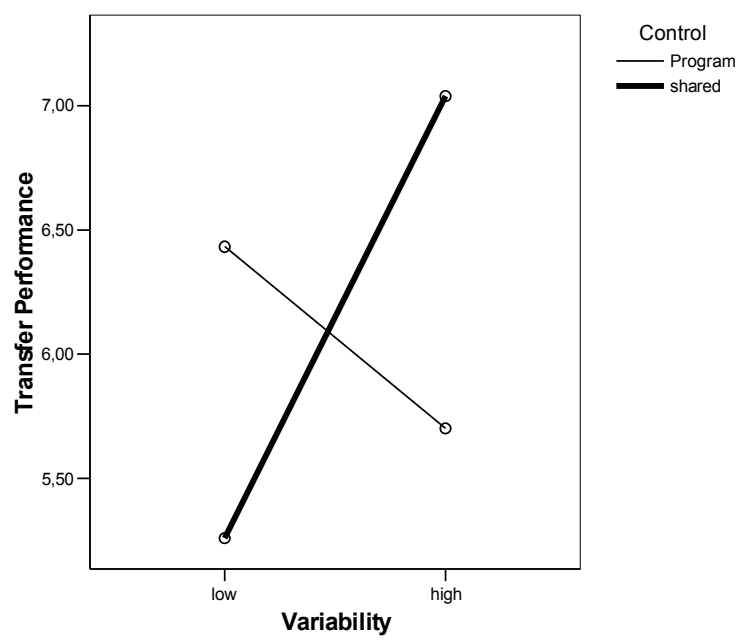

Interaction Effect on Task Involveme

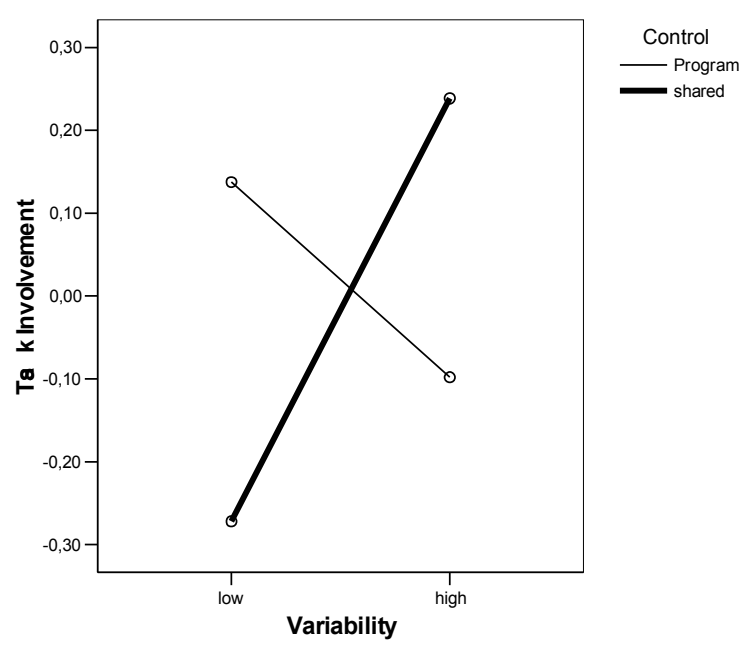

